\title{
Giant Ovarian Cysts: A Case Series
}

\author{
Utoo BT, ${ }^{1}$ Aba AP, ${ }^{2}$ Olagbaye OO. ${ }^{2}$ \\ 'Obstetrics \& Gynaecology Department, Benue State University Teaching Hospital, Makurdi. \\ ${ }^{2}$ Bethany Medical Centre Gboko.
}

*Corresponding Author: Dr. Utoo Bernard Terkimbi. Department of Obstetrics \& Gynaecology, Benue State University Teaching Hospital, Makurdi,GPO Box,239, Makurdi,Benue State,Nigeria.e-mail:bernardutoo@yahoo.com

\begin{abstract}
Giant ovarian cysts are rare and are almost no longer reported in medical literature. Except where good diagnostic imaging procedure is performed, they could be mistaken for massive abdominal ascites. Here we report 2 cases which were diagnosed at a medical missions facility during a free medical outreach program in March 2017. The patients presented with gross abdominal distention. Ultrasound scan revealed cystic ovarian tumors in both cases with no suspicious finding for malignancy. Salpingo-ophorectomies were carried out at laparatomies through midline incision extending from below the epigastric to just above the suprapubic. Patients were treated with postoperative antibiotics and analgesics and discharged home after 7 days on admission. They were followed up for 2 years and both recovered well without recurrence. Cystectomy without pre-operative drainage remains the modality of treatment in our environment.
\end{abstract}

Keywords: Ascites, Cystadenoma, Giantcyst, Ophorectomy, Tumor,Unilocular

\section{INTRODUCTION}

$\mathrm{B}$ enign cysts of the ovary are not uncommon, however, giant ovarian cysts presenting with massive abdominal distention are rare. ${ }^{1}$ Affected patients may be undiagnosed. ${ }^{1,2}$ However, when the tumor grows from been a pelvic mass to not just an abdominal-pelvic mass but up to the epigastric region, abdominal pains from cyst accidents and obstruction with associated nausea, vomiting, early satiety, constipation, respiratory difficulty etc could be some of the presenting features of the affected patient. ${ }^{2,3}$ If not properly evaluated, the gross abdominal distention could be diagnosed to be massive ascites such as the case reported by Yeika et al. ${ }^{3,4,5}$ Most of these tumors are benign serous or mucinous cyst adenomas; although few cases of low-grade malignant (adenocarcinomas) have been diagnosed. ${ }^{3}$

\section{CASE REPORT I}

Mrs. MM was a 21 year old para 1+0 (Alive), Tiv woman who was a housewife with secondary level of education. She presented with a history of progressive abdominal swelling of one year duration. She however did not experience abdominal pains, nausea, vomiting or change in bowel habits but there was associated weight loss. She 
had significant urinary symptoms and occasional mild dypsnea. She stopped menstruating two years after delivery. She spent about 4 months in a prayer house seeking for solution to her predicament.

She attained menarche at the age of 13 years, with menstrual flow of 4 days in a 28 to 30 day cycle. She was not on contraception. She had not done a pap smear in the past. She was a known retroviral disease patient on Highly Active Antiretroviral Therapy (HAART) for a year prior to presentation. The husband was a long distance driver who was also retroviral disease positive.

\section{Physical examination}

On general physical examination, she was chronically illlooking. She was afebrile, not pale, no sclera jaundice, or pedal edema. Her chest was clinically clear. Pulse rate was 82 beats per minute and blood pressure 110/70mmHg. Heart sounds were first and second only. The abdomen was distended, shiny with a flattened umbilicus. It was tense with symphysio-fundal height measuring $38 \mathrm{~cm}$. Abdominal organs were difficult to palpate. Fluid thrill was positive. Vagina examination revealed a normal vulva and vagina with a closed external cervical os.

\section{Investigation}

Pack cell volume (PCV) was 32\%, Blood Group O positive, two units of blood were grouped and cross-matched. VDRL, HBsAg, HCV, \& RVST were all negative, Renal function test (RFT), LFT \& urinalysis were all normal. Ultrasound showed a huge right sided multilocular adnexal mass echoluscent in appearance (see Figure 1)

Histological examination showed a big tumor, $18 \times 25 \times 28 \mathrm{~cm}$; with a glistening, smooth highly vascularized wall partly hemorrhagic and partly grayish, cystic in consistency (see Figure 2). Cut section through the mass revealed a yellowish fluid and shiny surface. Tumor was multilocular and weighed $11.3 \mathrm{~kg}$. Microscopically; histological section of tissue shows a cystic cavity lined by the inner granulosa cells and the outer theca interna cells. Areas of fibrosis, dilated blood vessels and atretic follicles were present. Elsewhere, the Fallopian tube with mucus membrane thrown into numerous papillary branching lined by ciliated columnar epithelium was also seen (see Figure 3).

\section{Intervention and outcome}

Right Salpingo-ophorectomy was carried out at laparatomy with midline incision extending from below the epigastric to

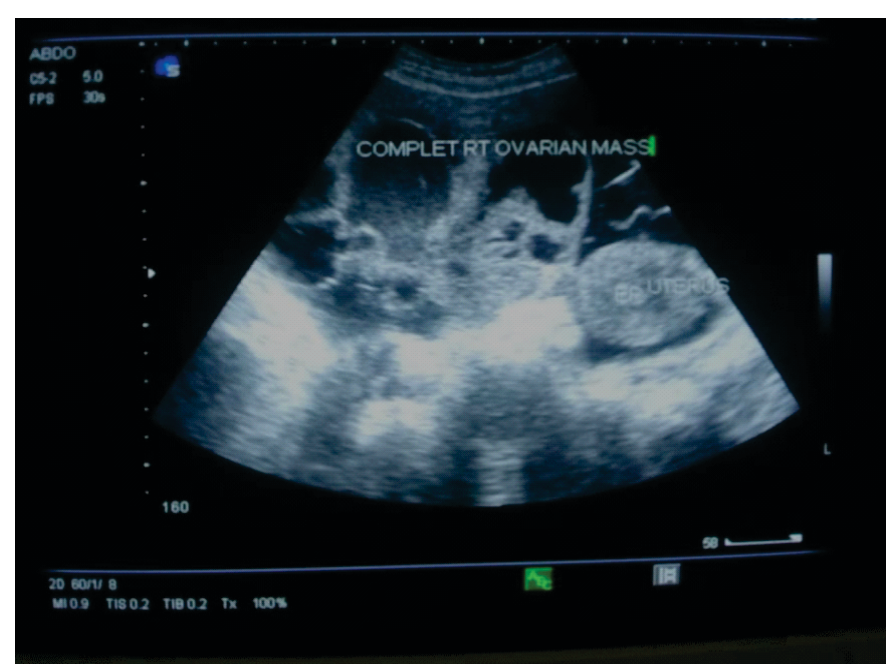

Figure 1: Radiological appearance of a huge right sided multilocular adnexal mass echoluscent in appearance..

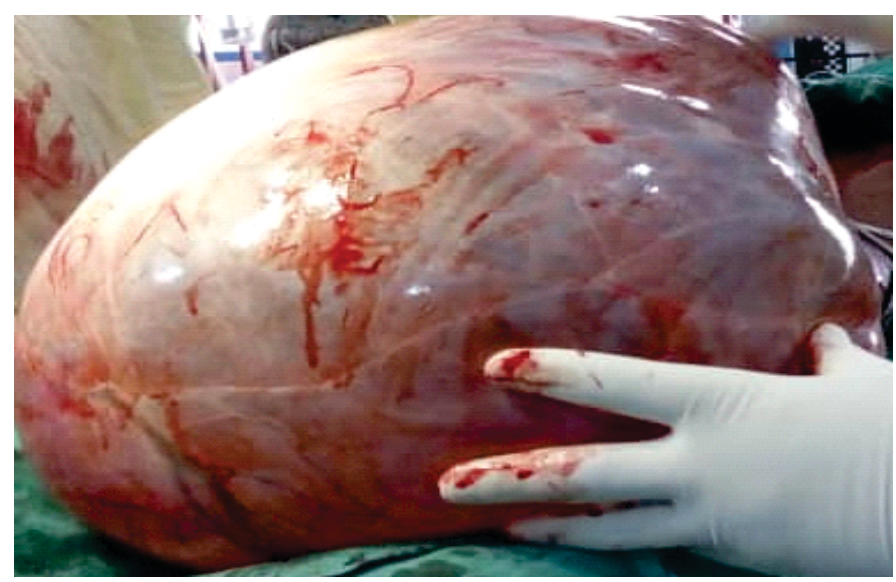

Figure 2: Gross appearance at laparatomy of big tumor, $18 \times 25 \times 28 \mathrm{~cm}$ with a glistening, smooth highly vascularized wall partly hemorrhagic and partly grayish, cystic in consistency.

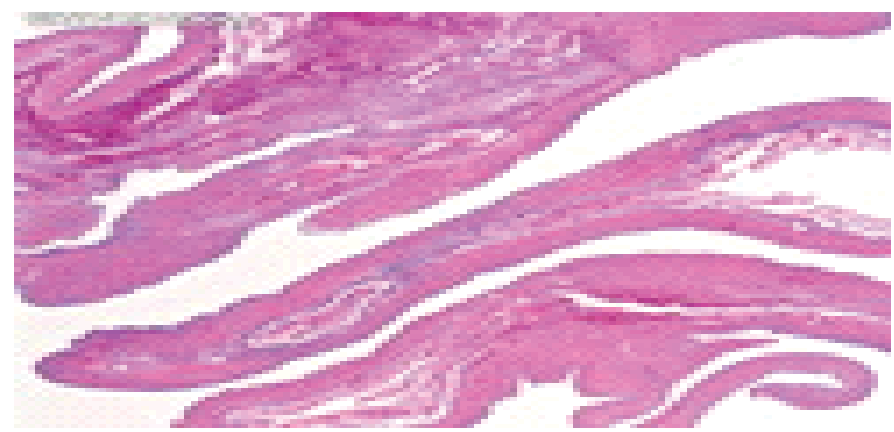

Figure 3: Histological section of tissue shows a cystic cavity lined by the inner granulosa cells and the outer theca interna cells. Areas offibrosis, dilated blood vessels and atretic follicles were present. 
just above the epigastric. Patient was thereafter treated with post operative intravenous fluids, antibiotics and analgesics and discharged home after 7 days on admission. She recovered well with good wound healing. There was no evidence of recurrence after 2 years of follow up. The wound had also healed well.

\section{CASE REPORT II}

Mrs. AL was a 35 year old Para1+1 (Alive) Tiv woman, a Christian and house wife who presented with a history of abdominal swelling of a year and 10 months duration. The swelling was said to be insidious in onset and progressive; but, with no associated abdominal pains. She had increased appetite, early satiety, occasional constipation but no change in bowel habit. She did not have history of weight loss or leg swelling. She has no significant urinary or respiratory symptoms. Her menarche was at 14 years and menstruated for 3-4 days in a 28 day cycle. She had used combined oral contraceptive pills as a teenager. She was aware of Pap smear but has not done it. She was the only wife of a driver who was a secondary school certificate holder.

\section{Physical examination}

On examination, she was a young woman not in any form of distress. She was not pale, anicteric, afebrile and with no pedal edema. Her chest was clinically clear. Pulse rate was 86 beats per minute with blood pressure of $120 / 80 \mathrm{mmHg}$. The abdomen was distended with a flattened umbilicus and moves with respiration. The symphysio-fundal height was $36 \mathrm{~cm}$. It was difficult to palpate for abdominal organs. Fluid thrill was positive. The Vagina examination revealed a normal vulva and vagina with a closed external cervical os.

\section{Investigation}

Packed cell volume (PCV) was 36\%, Blood Group A positive, and two units of blood were grouped and cross-matched. VDRL, HBsAg, HCV, \& RVST were all negative, Renal Function Test (RFT), LFT \& urinalysis were all normal. Ultrasound showed a huge Left sided multilocular adnexal mass echoluscent in appearance (see Figure 4)

Histological examination showed a huge multilocular, highly vascularized cystic mass measuring $18 \times 23 \times 25 \mathrm{~cm}$ that weighed $10.6 \mathrm{~kg}$ (see Figure 5 ). The cyst is lined with single layer of tall, cuboidal non-ciliated epithelium resembling ovarian surface epithelium, no atypia, no invation or distortion in architecture.

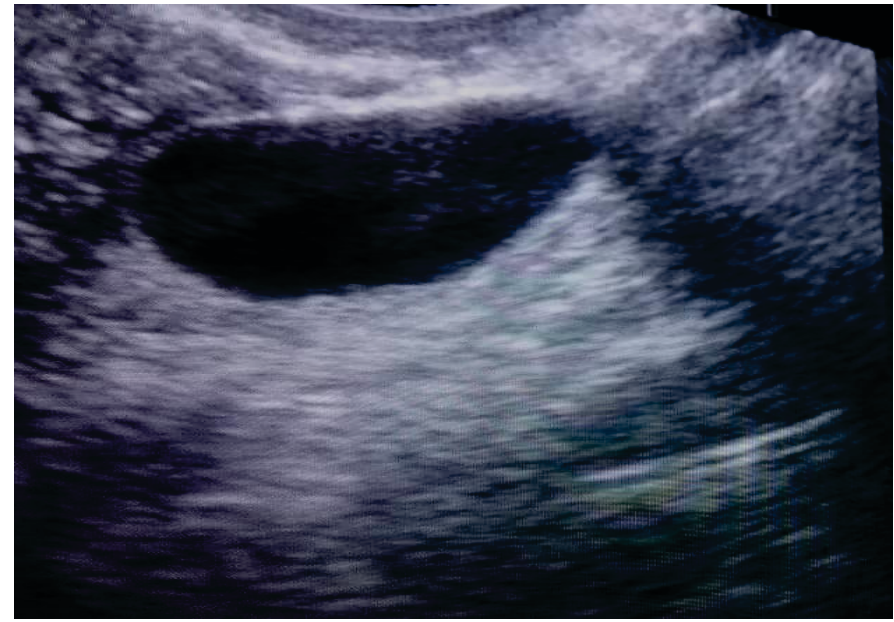

Figure 4: Ultrasound Scan appearance of a huge Left sided multilocular adnexal mass echoluscent in appearance.

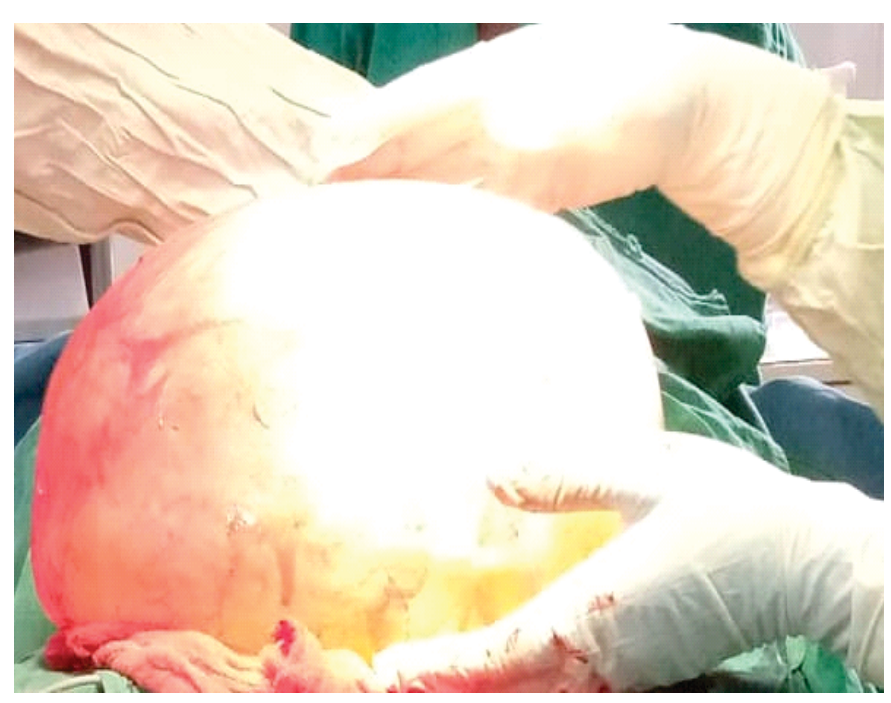

Figure 5: Gross appearance at laparatomy of a huge multilocular, highly vascularized cystic mass measuring $18 \times 23 \times 25 \mathrm{~cm}$ that weighed $10.6 \mathrm{~kg}$

\section{Intervention and outcome}

Left Salpingo-opherectomy was carried out at laparatomy with midline incision extending from below the epigastric to just above the suprapubic. Abdomen was closed in layers with vicryl sutures and haemostasis properly secured. Patient was thereafter treated with post operative intravenous fluids, antibiotics and analgesics and discharged home after 7 days on admission. She recovered well with good wound healing There was no evidence of recurrence after two years of follow up. 


\section{DISCUSSION}

It is reported in the literature that simple ovarian cyst are the most common benign adnexal masses. ${ }^{1}$ However, giant sized cysts such as reported in this study are rare. Ovarian cyst are generally said to be significantly large when they are more than $5 \mathrm{~cm}$ and are said to be giant in size when they are over $15 \mathrm{~cm}^{2}$ although Kiemtore et al., gave the cut off as $10 \mathrm{~cm}$ and above. ${ }^{6}$ They are usually found in young, nulliparous or low parity women such as we have reported. Typical of developing communities such as ours, these two cases reported late ${ }^{3}$. Each of our patients presented to hospital after a year. This is probably due to illiteracy, poverty and poor health seeking behavior of the women. In Africa, mystical beliefs also delay patients from seeking orthodox medical attention ${ }^{7}$. This was true of the cases managed. In fact one of the cases spent months in prayer houses seeking for spiritual solution to her predicament! The symptomatology reported in most literatures ranging from no complaints to symptoms of abdominal pain and some gastrointestinal disturbances which are dependent on the size of the mass were partly observed in our patients. ${ }^{3}$ However, worsening signs and symptoms such as suggest diaphragmatic compression namely; pulmonary edema, atelectasis and abdominal compartment syndrome were not observed in our patient. Also, there was no leg edema suggesting compression on the inferior vena cava. Although, imaging procedures such as Ultrasonography, CT scans, MRI and color Doppler are useful in diagnosis, ${ }^{8}$ it is worthy to mention at this point that, misdiagnosis could be done which unfortunately may lead to suboptimal care administered to the patient as observed by Mikos et al. ${ }^{4}$ Some had misdiagnosed giant ovarian cysts as ascites. ${ }^{5}$ Other differentials could be uterine masses, hydronephrosis, mesenteric tumors, pancreatic pseudocyst, bladder distention etc. ${ }^{9}$ If in doubt, higher imaging can be done with the complement of colour Doppler to enhance the degree of accuracy. ${ }^{10}$ Pre-operative drainage of the mass predisposes the patient to peritonitis and intra-peritoneal dissemination of tumor cells in case of malignancy or gelatinous disease of the peritoneum in case of mucinous cyst adenoma. ${ }^{3}$ Advocates of pre-operative drainage support their decision on relieving the patient from respiratory and cardiovascular complications. Some clinicians had reported laparoscopic approach to surgical removal. ${ }^{3,11}$ The popular approach however is by open laparatomy which pose less risk to cyst rupture. ${ }^{12}$ In most centers in our environment; the lack of equipment, cost of the surgery and absence of skill makes laparoscopic approach unfavorable even if desirable. Our patient had open surgery with the midline abdominal incisions for easy delivery of the cysts without rupturing the mass as demonstrated in figure 2 $\& 5$ above. It is reported that over $70 \%$ of these tumors are benign. They are said to be mainly serous or mucinous cyst adenomas. Malignancies are less common $(20-25 \%))^{3,12,13}$ The two cases managed were serous cyst adenomas. The patients had salpingo-ophorectomies and were followed up for 2 years. There was no evidence of recurrence in any of the cases. Again the abdominal wounds healed well. In some cases reports of abdominoplasty has been reported which was not the case in the management of our patients. ${ }^{13}$

\section{CONCLUSION}

Giant ovarian cysts are not common. Early diagnosis through imaging technique like ultrasonography is critical to treatment. We advocate for laparatomy and non pre-operative drainage in our environment.

\section{Acknowledgment}

We are grateful to the Gynaecology ward nurses of Bethany Medical Center (BMC) for the postoperative care to our patients. We thank Mrs. Asunawinne Jessie Eche the Anesthetic Nurse.

\section{Conflict of interest}

The authors declare no conflict of interest

\section{REFERENCES}

1. Duran A, Duran FY, Cengiz F, Duran O. Intestinal Necrosis due to Giant Ovarian cyst: A case report in Surgery, 2013, A r t i c 1 e I D $831087, \quad 3$ p a g e s . http://dx.doi.org/10.1155/2013/831087.

2. Dolan MS, Boulanger SC, Salameh JR. Laparoscopic management of Giant Ovarian Cyst. JSLS, 2006; 10:254256.

3. Diop B, Niang MM, Ba PA, Toure PS, Abdou SY, Wane Y, et al. Management of Giant Ovarian Cyst: A report of 5 Cases. J Gynecol Surg 2016; 32(3):162-167.

4. Mikos T, Tabakaoudis GP, Pados G, Eugenidis NP, Assimakopoulos E. Failure of Ultrasound to diagnose Giant Ovarian Cyst: A case Report. CASE Journal 2009; 2:6909.

5. Yeika EV, Efie DT, Tolefac PN, Fomengia JN. Giant 
Ovarian Cyst Masquerading as a massive ascites: a case report. BMC Res 2017; 10:749.

6. Kiemtore S, Zamane H, Sawadogo YA, Sib RS, Komboigo E, Ouedraogo A, Bonane B. Diagnosis and management of a giant ovarian cyst in the gravid-peurperium period: a case report. BMC pregnancy and childbirth 2019:19:523.

7. Utoo BT. Malignant Germ Cell Tumour in Adolescent Nigerian: Diagnostic Dilemma and Management. J Gynecol Surg, 2012;28(5):382-384.

8. Kassidi F, Moukit M, Ait EF, El Hassani ME, Guelzim k, babahabiba, Kouach J, moussaoui RD, Dehayni M. Successful management of a giant ovarian cyst: A case report. Austin Gynecol case report 2017; 2(1): 1012.

9. Paltaci I, Diner G,Kartufan FF, Urfalioglu M. Giant ovarian cyst that may be confused with mesentery cyst: Case Report 2014;5(6):326-328.

10. Young T-H, Lee H-S. Giant Ovarian Cyst. N Eng J Med, 2008; 358:20.

11. Saeed B, Feras S, Sameer S. Complete Extirpation of a giant ovarian cyst in an adolescent: case Reports in Obstet Gynaecol 2017; Article ID 7632989, 3 pages.

12. Patel N, Dupis G, Wild R.Giant Ovarian cyst in an adolescent with PCOS.CONSULTANT 2014; 54(1):41-43.

13. Masamitsu K, Akira t, Satoshi, Y Yuji Y, Hideki A, Chikako S, Takashi N. A case of abdominoplasty after removal of giant ovarian cyst. Plast Reconst Surg Glob Open 2014; 2:e195. 